УДК 629.424.1

\title{
ПРОГНОЗУВАННЯ РЕСУРСУ ВІДПОВІДАЛЬНИХ ДЕТАЛЕЙ ЛОКОМОТИВІВ
}

Д-р техн. наук О.Б. Бабанін, асп. В.І. Бульба, О.В. Борисенко, А.М. Стецура

\section{ПРОГНОЗИРОВАНИЕ РЕСУРСА ОТВЕТСТВЕННЫХ ДЕТАЛЕЙ ЛОКОМОТИВОВ}

Д-р техн. наук А.Б. Бабанин, асп. В.И. Бульба, А.В. Борисенко, А.М. Стецура

\section{PROGNOZUVANNYA RESOURCES VIDPOVIDALNIH PARTS LOKOMOTIVIV}

Dr. of techn. sciences O.B. Babanin, V.I. Bulba, O.V Borisenko, A.M. Stetsura

У статті наведений аналіз існуючих методів визначення зношування відповідальних вузлів тертя локомотивів. Запропонована методика прогнозування зносу відповідальних деталей на підставі накопичених даних, яка дозволяє отримати математичне рівняння зношування. Екстраполячія ичього рівняння за граничним значенням зносу дає можливість одержати інтервал роботи локомотива, у якому необхідно приймати відповідні дї щодо заміни або ремонту даного вузла.

Ключові слова: відмова, експлуатачія, знос, крива зносу, модель, накопичення, параметр, прогнозування, прочес, реалізація, рівняння.

В статье приведен анализ сущеествующих методов определения изнашивания ответственных узлов трения локомотивов. Предложена методика прогнозирования износа ответственных деталей на основании накопленных данных, которая позволяет получить математическое уравнение изнашивания. Экстраполяция этого уравнения по предельному значению износа дает возможность получить интервал работы локомотива, в котором необходимо принимать соответствующие действия по замене или ремонту данного узла.

Ключевые слова: отказ, эксплуатация, износ, кривая износа, модель, накопление, параметр, прогнозирования, процесс, реализащия, уравнение.

In article the analysis of existing methods of definition of wear process of responsible units of friction of locomotives is resulted. The technique of forecasting of deterioration of responsible details on the basis of the saved saved data which allows receiving the mathematical equation of wear process is offered. Extrapolation of this equation on limiting value of deterioration enables to receive an interval of work of the locomotive in which it is necessary to accept corresponding actions on replacement or repair of the given unit.

Keywords: failure, maintenance, depreciation, depreciation curve, model, storage, setting, forecasting, process implementation, equation.

Постановка проблеми в загальному вигляді, іiї зв'язок із важливими науковими та практичними завданнями. Продовження термінів служби тягового рухомого складу (ТРС) змушує шукати нові підходи й методи оцінки їх технічного стану. Цього можна досягти тільки застосуванням у технології обслуговування 
й ремонту сучасних наукових методів, що дозволяють виявляти й попереджати відмови, підтримувати експлуатаційні показники в заданих межах. Практика показує, що втрата працездатності й відмови відповідальних деталей ТРС найчастіше пов'язані 3 їх значним зношенням. Зміна лінійних розмірів деталей, виникнення пошкоджень тертьових поверхонь від викришування матеріалу, задирок, відшаровувань і ін. порушують їх нормальне функціонування в експлуатації й підвищеному бракуванні при ремонті. Тому прогнозування зношування тертьових пар має дуже важливе значення для забезпечення надійної експлуатації локомотивів.

Аналіз останніх досліджень i публікацій. Проблемі зносостійкості й втомного зношування постійно приділялося центральне місце. Уперше модель втомного зношування була побудована I.B. Крагельським [2]. Однак у переліку основних допущень, прийнятих у даних методиках, надалі відзначалося неприпустимо велике відхилення результатів розрахунків від дійсності. Не випадково, що надалі в трибології [5] формули моделі І.В. Крагельского назвали "громіздкими й малопридатними для інженерних розрахунків". За останні роки модель втомного руйнування описувалася в довідковій літературі й удосконалювалася. Складність механізму зношування, різноманіття його видів i недостатню вивченість зв'язків із факторами, що впливають на них, можна оцінювати тільки на підставі досвіду експлуатації [3]. Варто вказати на появу в цей час нового теоретичного підходу до розрахунку вузлів тертя на зносостійкість [1], на інтенсивно нарощуваний фонд експериментальних досліджень (як закордонних, так i вітчизняних [5]), які дають фізичну основу нових методів розрахунку.

Мета дослідження. Сьогодні кількісні дані щодо зносостійкості відповідальних деталей ТРС базуються, як правило, на результатах вимірювання й аналізу їх товщини і є єдиним параметром оцінки зносу, за яким судити про протікання зношування практично неможливо. Сучасний стан ТРС i збільшення його терміну служби вимагає диференційованого вивчення тертя, що відбувається у відповідальних вузлах, 3 метою подальшого прогнозування їхнього ресурсу.

Виклад основного матеріалу дослідження. Зношування в різних вузлах тертя є складним процесом, що залежить від великої кількості факторів. Зі збільшенням тривалості роботи вузла відбувається поступова зміна умов зношування, змінюються умови змащення, динамічний режим навантаження, умови тепловідведення, характер взаємодії деталей у вузлі й т.д.

Установлено, що в умовах експлуатації зношування вузлів тертя відповідальних деталей дизелів тепловозів (циліндрових гільз, підшипників колінчастого вала й ін.) розвивається як випадковий процес із відносно великою дисперсією зношення. Тому для опису такого процесу найбільш прийнятною $\epsilon$ імовірнісна математична модель, у якій необхідні принаймні три рівняння. Перше 3 них повинне задовільно виражати математичне сподівання випадкового процесу накопичення зносу за часом, тобто не випадкову складову процесу зношування, друге рівняння - верхню довірчу межу випадкового процесу, тобто криву, про яку із заданим ступенем ризику можна сказати, що жодна реалізація процесу зношування не пройде вище іiі, а третє - нижню довірчу межу процесу накопичення зносу. Ці рівняння в сукупності утворюють імовірнісну математичну модель процесу зношування.

Обробка зібраних статистичних даних щодо циліндрових гільз тепловозних дизелів дозволила зробити висновок про нелінійний характер процесу їхнього зношування. Було встановлено, що 
швидкість зношування циліндрових гільз $\overline{\boldsymbol{v}}$ $\epsilon$ функцією величини накопиченого зносу $\boldsymbol{\delta}$ [7]

$$
\bar{v}=\frac{d \delta}{d t}=f(\delta),
$$

де $\boldsymbol{t}$ - тривалість роботи вузла.

Рівняння (1) можна подати у вигляді нескінченного статечного ряду

$$
\frac{d \delta}{d t}=c+k \delta+k_{1} \delta^{2}+\ldots+k_{n-1} \delta^{n}
$$

У лінійній моделі використовують тільки перший член цього ряду, вважаючи, що швидкість зношування залишається постійною протягом усього періоду експлуатації. У нелінійній моделі сильний кореляційний зв'язок між швидкістю зношування й накопиченим зносом дозволяє обмежитися тільки двома першими членами ряду (2), нехтуючи іншими. Перетворюючи рівняння (2), інтегруючи ліву й праву його частини відповідно за часом і зносом та вважаючи, що при напрацюванні $\boldsymbol{t}_{1}$ середня величина зносу дорівнює $\boldsymbol{\delta}_{1}$, будемо мати

$$
\boldsymbol{t}-\boldsymbol{t}_{1}=\frac{1}{k} \ln \frac{c+\boldsymbol{k} \bar{\delta}}{c+k \overline{\delta_{1}}}
$$

Переходячи до десяткових логарифмів одержимо

$$
\boldsymbol{t}-\boldsymbol{t}_{1}=\frac{1}{\boldsymbol{k} \lg \boldsymbol{e}} \lg \frac{\frac{\boldsymbol{c}}{\boldsymbol{k}}+\overline{\boldsymbol{\delta}}}{\frac{\boldsymbol{c}}{\boldsymbol{k}}+\boldsymbol{\delta}_{1}}
$$

Позначивши частки виразу (4) як

$$
\boldsymbol{A}=\frac{1}{\boldsymbol{k} \lg \boldsymbol{e}},
$$

$$
\boldsymbol{h}=\frac{\boldsymbol{c}}{\boldsymbol{k}},
$$

i підставивши їх у рівняння (4) та розв'язавши його щодо середнього зносу $\boldsymbol{\delta}$, одержимо експоненціальне рівняння, що виражає математичне сподівання процесу зношування

$$
\bar{\delta}=\left(\overline{\delta_{1}}+\boldsymbol{h}\right) \cdot e^{\frac{t-t_{1}}{A}}-\boldsymbol{h}
$$

Вираз $\boldsymbol{A}$, який вимірюється в одиницях напрацювання (годинах або кілометрах пробігу), визначає форму кривої зносу й інтерпретується як коефіцієнт довговічності. Величина $\boldsymbol{h}$ вимірюється в одиницях зносу (мм, мкм). Вона визначає положення кривої відносно початку координат і $\epsilon$ коефіцієнтом iї зсуву. Величина його дорівнює відстані від початку координат до асимптоти цієї кривої, узятої зі зворотним знаком.

Експоненціальне рівняння припускає нормальний розподіл зносу для будь-якого моменту часу. У цьому випадку верхню й нижню довірчі межі процесу зношування можна описати тим самим експоненціальним рівнянням

$$
\begin{aligned}
& \delta^{\prime}=\left(\overline{\delta_{1}}+\boldsymbol{t}_{\beta} \cdot \sigma_{1}+\boldsymbol{h}\right) \cdot e^{\frac{t-t_{1}}{A}}-\boldsymbol{h}, \\
& \delta^{\prime \prime}=\left(\overline{\delta_{1}}-t_{\beta} \cdot \sigma_{1}+\boldsymbol{h}\right) \cdot e^{\frac{t-t_{1}}{A}}-\boldsymbol{h}
\end{aligned}
$$

де $\boldsymbol{\delta}^{\prime}$ - поточна верхня довірча межа зносу;

$$
\sigma_{1} \text { - середньоквадратичне відхилення }
$$
зношування при тривалості роботи $\boldsymbol{t}_{1}$;

$\boldsymbol{t}_{\boldsymbol{\beta}}$ - табличний коефіцієнт, що залежить від прийнятої довірчої ймовірності $\beta$.

$$
\text { Підставивши в рівняння (8) i }
$$
замість $\boldsymbol{\delta}^{\prime}$ і $\boldsymbol{\delta}^{\prime \prime}$ значення верхніх і нижніх довірчих меж у момент часу $\boldsymbol{t}_{2}$ й розв'язавши їх спільно, одержимо вираз для визначення величин $\boldsymbol{A}$ i $\boldsymbol{h}$ 


$$
\begin{gathered}
\boldsymbol{A}=\frac{\boldsymbol{t}_{2}-\boldsymbol{t}_{1}}{\lg \frac{\boldsymbol{\sigma}_{2}}{\boldsymbol{\sigma}_{1}}}, \\
\boldsymbol{h}=\frac{\overline{\boldsymbol{\delta}}_{2}-\overline{\boldsymbol{\delta}}_{1} \frac{\boldsymbol{\sigma}_{2}}{\boldsymbol{\sigma}_{1}}}{\frac{\boldsymbol{\sigma}_{2}}{\boldsymbol{\sigma}_{1}}-1},
\end{gathered}
$$

де $\delta_{2}$ і $\sigma_{2}$ - середнє зношування і його середньоквадратичне відхилення в момент часу $\boldsymbol{t}_{2}$.

Рівняння (7) - (11) дають можливість за допомогою статистичного дослідження зношень деталей локомотивів, що були в експлуатації протягом двох значень напрацювання $\boldsymbol{t}_{1}$ i $\boldsymbol{t}_{2}$, які досить відрізняються одне від одного, знайти рівняння математичного сподівання й рівняння довірчих меж процесу зношування вузла у випадкових реально існуючих умовах експлуатації.

На підставі вищевикладеного запропонована методика, що передбачає такі етапи математичної обробки отриманої статистичної інформації про зношення вузлів тертя в експлуатації й прогнозування цього процесу:

- побудова кореляційної таблиці залежності зносу від напрацювання деталі;

- перевірка неусічення розподілів зношення й однорідності вихідних даних;

- вибір і перевірка законів розподілу зношення для різних інтервалів напрацювань;

- визначення середніх значень зношення i його середньоквадратичного відхилення для різних інтервалів наробітків;

- вибір математичної моделі процесу зношування;

- побудова рівнянь зношування й екстраполювання кривих зношення за межі періоду спостережень.
Знаючи величину небезпечної межі зношення $\boldsymbol{\delta}_{\boldsymbol{\sigma} \boldsymbol{p}}$, можна за допомогою експоненціальної імовірнісної моделі визначити середню $\boldsymbol{T}_{\boldsymbol{c}}$, мінімальну $\boldsymbol{T}_{\boldsymbol{m} \boldsymbol{i n}}$ i максимальну $\boldsymbol{T}_{\boldsymbol{m a x}}$ межі довговічності деталі.

У результаті цього одержимо

$$
\begin{aligned}
& T_{c p}=A \lg \frac{\delta_{\sigma p}+h}{\delta_{1}+h}+t_{1} \\
& \boldsymbol{T}_{\min }=\boldsymbol{A} \lg \frac{\boldsymbol{\delta}_{\tilde{\sigma} p}+\boldsymbol{h}}{\delta_{1}+\boldsymbol{t}_{\beta} \sigma_{1}+\boldsymbol{h}}+\boldsymbol{t}_{1} \\
& \boldsymbol{T}_{\max }=\boldsymbol{A} \lg \frac{\boldsymbol{\delta}_{\tilde{\sigma} p}+\boldsymbol{h}}{\boldsymbol{\delta}_{1}-\boldsymbol{t}_{\boldsymbol{\beta}} \sigma_{1}+\boldsymbol{h}}+\boldsymbol{t}_{1} \text {. }
\end{aligned}
$$

Як приклад на підставі даної методики була визначена залежність зношування циліндрових гільз дизелів тепловозів ЧМЕЗ. Перейшовши у виразах (12) - (14) від десяткових логарифмів до натуральних та приймаючи, що напрацювання роботи маневрових тепловозів визначається не в кілометрах пробігу, а в натуральному годинному часі $T$, одержимо рівняння зношування циліндрових гільз у такому вигляді

$$
\begin{aligned}
& \bar{\delta}=0,13 \cdot e^{\frac{T-98,5}{13,7}}+0,065, \\
& \boldsymbol{\delta}^{\prime}=0,173 \cdot e^{\frac{T-98,5}{13,7}}+0,065 \\
& \boldsymbol{\delta}^{\prime \prime}=0,087 \cdot e^{\frac{\boldsymbol{T}-98,5}{13,7}}+0,065 .
\end{aligned}
$$

Задаючись різними значеннями напрацювання та підставляючи його $\mathrm{y}$ вирази (15) - (17), одержуємо розрахункові значення зношення циліндрових гільз, за якими побудовані графічні залежності, наведені на рисунку. 


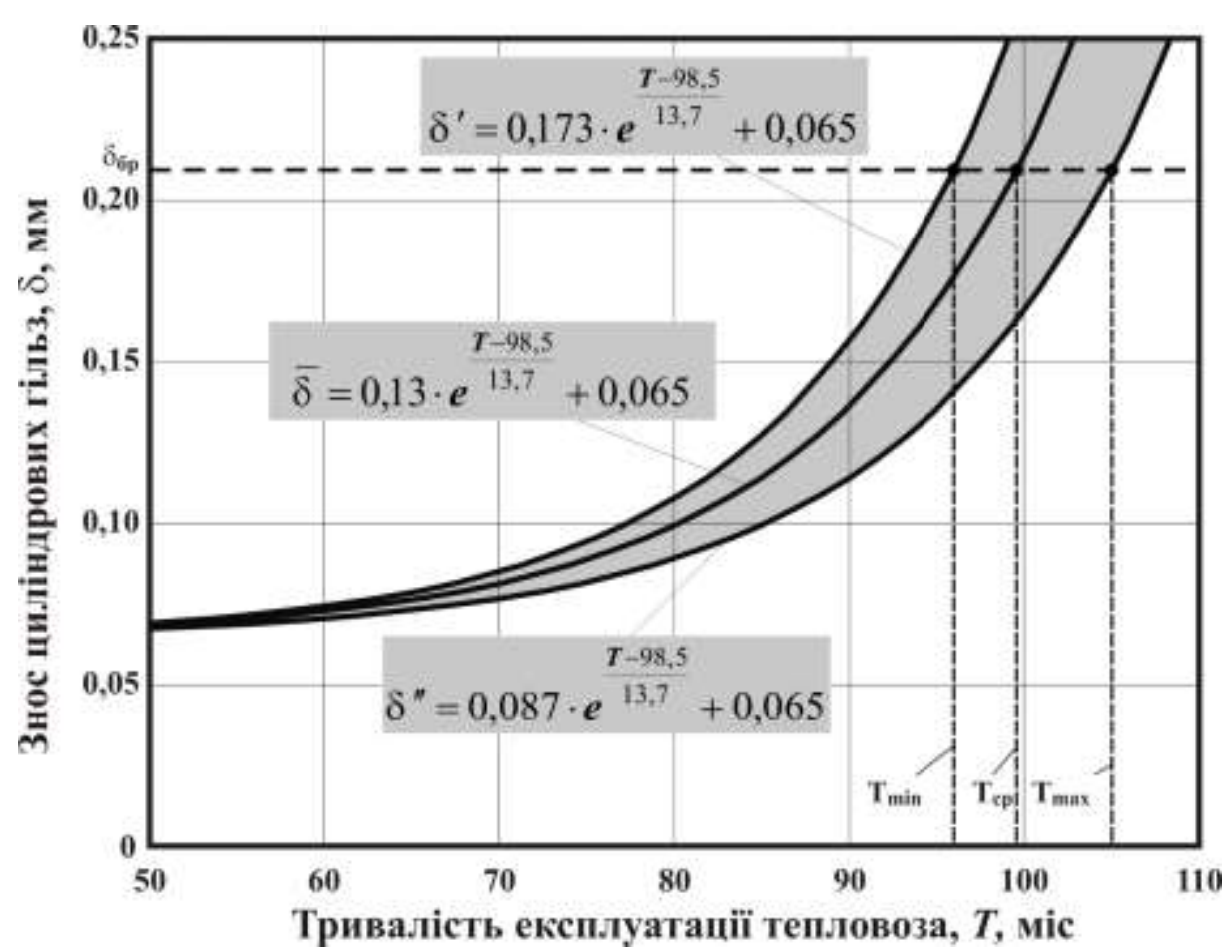

Рис. Залежність середнього зносу $(\overline{\boldsymbol{\delta}})$, нижньої $\left(\boldsymbol{\delta}^{\prime \prime}\right)$ і верхньої $\left(\boldsymbol{\delta}^{\prime}\right)$ меж його відхилень залежно від тривалості експлуатації циліндрових гільз дизелів тепловозів ЧМЕЗ

3 отриманих графічних залежностей, задаючись бракувальним зношенням $\delta_{\text {бр }}$, можна визначити середню, мінімальну й максимальну довговічність циліндрової гільзи. При бракувальному значенні $\delta_{\tilde{\sigma}}=0,22 \mathrm{Mм}$ напрацювання складе: $\boldsymbol{T}_{\min }=95,3$ місяця або 7,9 року, $\boldsymbol{T}_{\boldsymbol{c}}=99,3$ місяця або 8,3 року й $\boldsymbol{T}_{\max }=104,8$ місяця або 8,7 року.

\section{Висновки 3 дослідження й} перспективи, подальший розвиток у даному напрямку:

1. Виконано аналіз існуючих методик визначення зношування відповідальних вузлів тертя ТРС. Виявлено, що для визначення їхнього зношення необхідний принципово новий підхід, що враховує його старіння та різні фактори, що діють в експлуатації.

2. Запропоновано математичну модель, яка на підставі статистичних даних ураховує нелінійний вид процесу зношування відповідальних деталей ТРС. На підставі даної моделі за статистичними даними вимірів величин зносу у фіксовані моменти часу можна спрогнозувати реальне значення тривалості експлуатації різних вузлів.

3. Як приклад визначена залежність зношення й розраховані середні значення довговічності при досягненні бракувальних зносів в експлуатації циліндрових гільз дизелів тепловозів ЧМЕ3.

\section{Список використаних джерел}

1. Бажинов, А.В. Исследование износа сопряжений силовых агрегатов автомобиля от внешних условий [Текст] / А.В. Бажинов // Вестник ХГПУ: сб. науч. тр. - Харков: ХГПУ, 2000. - Вып. 124. - С. 100-105. 
2. Крагельский, И.В. Основы расчетов на трение и износ [Текст] / И.В. Крагельский, М.Н. Добычин, В.С. Камбалов. - М.: Машиностроение, 1977. - 526 с.

3. Крылов, К.А. Долговечность узлов трения самолетов [Текст] / К.А. Крылов. - М.: Транспорт, 1996. - 183 с.

4. Кузьменко, А.Г. Модели переходных процессов при изнашивании [Текст] / А.Г. Кузьменко, В.А. Кузьменко // Проблеми трибології. - 1997. - №3. - С. 81-117.

5. Основы трибологии (трение, износ, смазка) [Текст] / под ред. А.В. Чичинадзе. - М.: Наука и техника, 1995. - 778 с.

6. Тартаковский, И.Б. Корреляционное уравнение износа [Текст] / И.Б. Тартаковский // Вестник машиностроения. - 1968. - №2. - С. 8-11.

7. Хрущев, М.М. Классификация условий и видов изнашивания деталей машин [Текст] / М.М. Хрущев // Трение и износ в машинах. - 1953. - Вып. 3. - С.5-17.

Бабанін Олександр Борисович, д-р техн. наук, профессор, кафедра експлуатації та ремонту рухомого складу. Бульба В.І., аспірант.

Борисенко Олександр Володимирович, слухач групи МЗ-Л-Б-11.

Стецура Андрій Миколайович, слухач групи МЗ-Л-Б-11.

Babanin O.B., dr. of techn. sciences; Bulba V.I., Borisenko O.V., Stetsura A.M. 